\title{
Origamic Architecture: um método de execução
}

Origamic Architure: a method of execution

\author{
> Isabela Guesser Schmitt \\ Universidade Federal de SC, Brasil \\ isagschmitt@hotmail.com \\ > Luiz Gonzaga Philippi Filho \\ Universidade Federal de SC, Brasil \\ zagaphilippi@gmail.com
}

> Regiane Trevisan Pupo

Universidade Federal de SC, Brasil

regipupo@gmail.com

\begin{abstract}
The origamic architecture consists of a paper architecture technique developed by Masahiro Chatani, which suggests the compilation of three other techniques: origami (fold), Kirigami (cut) and pop-up (mounting). The application of these techniques altogether results in a self-mounted volumetric model made of one sheet of paper. The aim of this paper is to show and explore a method to create $3 \mathrm{D}$ representations of architecture buildings as well as sketches through these techniques. The use of CAD systems and laser cut to materialize the models is also discussed.
\end{abstract}

Keywords: Origamic; Architecture; laser cut; Materialization; Representation.

\section{Introdução}

Inevitavelmente, quando as novas tecnologias digitais são utilizadas durante o processo projetual, haverá, em algum momento, a passagem do virtual para o material. Neste intervalo, a materializaçáo se torna o ponto-chave do processo de projeto: “... não é o processo de produçáo que define o projeto; é o projeto que determina a produção" (Hermmerling, 2011). Isso significa que a simples materialização da informação digital (produção de maquetes e protótipos) é diferenciada quando envolve estudos aprofundados acerca da melhor aplicaçáo de materiais em determinado projeto, por meios computacionais.

Semelhante a esse processo, a produção de origamis arquitetôni$\cos$ (origamic architecture), objeto de estudo desta pesquisa, envolve diferentes etapas, desde a informação digital até a sua materialização. A passagem entre o virtual e material se dá por meio de padróes de cortes e dobraduras previamente estabelecidos, que darão origem a diferentes representaçóes de objetos e também de obras de arquitetura.

A concepçáo dos modelos é geralmente utilizada para representaçóes de obras arquitetônicas já existentes, mas sua aplicação pode ser ampliada para as fases projetuais de uma edificação, por exemplo, como ferramenta de visualização dos volumes e composiçóes criados. Para isso, há a necessidade de estudos de modelagem digital, planificações, sistemas CAD (Computer-Aided-Design), geometria descritiva, além da compreensão de como o origami arquitetônico pode ser um veículo de entendimento espacial e tridimensional.

O produto digital obtido é a planificação, gerada a partir de todos esses estudos e tem a sua materializaçáo no modelo do origami arquitetônico, executado com o auxilio de tecnologias de corte laser e, posteriormente, montado. Deste modo, esta pesquisa visa estudar a relação entre modelagem digital e corte a laser na produção desses modelos e a criação de uma metodologia para concepção e elaboração de origamis arquitetônicos. A tecnologia do corte a laser utilizada como ferramenta para materialização dos modelos teve sua importância no desenvolvimento da técnica, onde os estudos puderam avançar mais rapidamente com a sua utilização, que produz modelos precisos, possibilitando um maior número de testes até a sua elaboração final.

\section{Desenvolvimento}

A representação tridimensional dos objetos, seja digital ou física, permeia todo o processo de projeto, desde sua etapa inicial até a sua produção final. A produção de maquetes ou mesmo protótipos está cada vez mais vinculada ao processo de criação, estabelecendo uma relação direta entre concepção e visualização.

A materialização do origami arquitetônico é possível por meio de um estudo da forma e volumetria do projeto, suas relaçóes geométricas e elementos construtivos, para que sua planificaçáo seja produzida. Acredita-se que esta planificaçáo de projetos de arquitetura e sua posterior montagem, em maquetes de escalas reduzidas, possam compreender outra forma de se representar e estudar elementos arquitetônicos. Apesar da técnica do origami arquitetônico utilizar materiais simples como uma folha de papel, pode expressar, além das características primordiais da obra representada, a volumetria, proporçóes, detalhes construtivos, etc. 


\section{Arquitetura de papel}

A arte de criar objetos somente com dobras é denominada origami. É composta por diversas composiçóes geométricas no papel que criam uma estrutura tridimensional (Figura 1a). Já o kirigami, é a arte de recorte do papel, sendo uma variante do origami, que utiliza os recortes para criar novas formas (Figura 1b). Por fim, a técnica do рор ир, comumente utilizada nos cartóes e livros infantis, se apropria dessas duas artes, onde a estrutura tridimensional é formada pelos cortes e suas dobras, podendo ser colados e adicionados outros pedaços de papéis (Figura 1c). a)

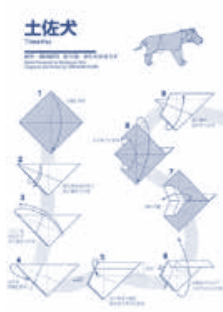

b)

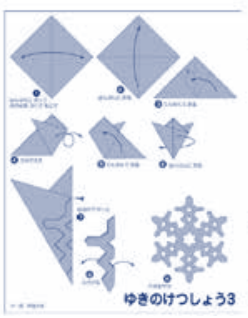

c)

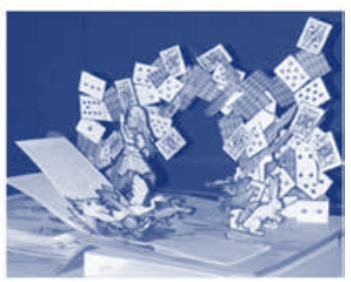

Figura 1: a): origami tradicional (Papiromano, 2014); b): exemplo de kirigami (Papiromano, 2014); c): Carroll, 2010).

Segundo Ueno (2003), o termo origami arquitetônico surgiu somente em 1981, por Masahiro Chatani, um professor de arquitetura do Instituto de Tecnologia de Tóquio. Nesta técnica são compiladas as três técnicas descritas acima, a dobradura do origami, o recorte do kirigami e o mecanismo de montagem do pop up. Outras terminologias também são encontradas para designar essa mesma técnica como: pop-up architecture, paper architecture, $3 D$ card e kirigami tridimensional (como ficou conhecido no Brasil).

No campo da arquitetura, a técnica vem sendo empregada na representação de monumentos e edificaçóes reconhecidas. Inicialmente, os primeiros modelos de origami arquitetônico foram concebidos através de um processo de tentativa e erro (Mitani, 2003). Com a evolução dessa técnica foi criada uma base teórica desenvolvida por Masahiro Chatani, para elaboração de diferentes formas e modelos.

\section{Tipos de origami arquitetônico}

A técnica de origami arquitetônico é concebida por cortes e dobras em uma folha de papel, que quando montada gera uma estrutura tridimensional. $\mathrm{O}$ ângulo de abertura da folha de papel define quatro tipos de origami arquitetônico: $0^{\circ}, 90^{\circ}, 180^{\circ}$ e $360^{\circ}$. Os modelos de $90^{\circ}$ são os mais utilizados para representaçáo de obras arquitetônicas, pois constituem uma modalidade que permite uma maior exploração de detalhes e ao se destacar do papel, ressalta a sua tridimensionalidade. Para que esse tipo de origami seja executado, é necessária a aplicaçáo de conceitos geométricos visando a precisão de dobras e cortes no fechamento do modelo além de proporção, volumetria e profundidade. Este tipo de modelo utiliza somente uma folha de papel e os efeitos são proporcionados pelos cortes e dobras, de acordo com a geometria descritiva (Figura 2a).

Já os modelos de $180^{\circ}$, podem ser definidos também como pop-ups, de maneira que as formas sáo visualizadas quando o mesmo é aberto a $180^{\circ}$ (Figura 2b). Para sua confecção é necessário um planejamento de encaixe ou colagem de novos papéis, que juntos montam a estrutura tridimensional quando aberto. Semelhante aos modelos de $90^{\circ}$, quando fechados as dobras se ajustam até se tornarem planas.

Os modelos de $360^{\circ}$ geram a estrutura tridimensional por completo. Esta técnica também desenvolvida por Masahiro Chatani, foi elaborada através do estudo de cubos e outras formas geométricas, quase sempre constituídas de formas simétricas (Figura 2c). Por último, nos modelos com $0^{\circ}$ de abertura, também é formada apenas por uma única folha de papel como os de $90^{\circ}$, mas que aparenta possuir várias camadas de papel, ressaltando a ideia de tridimensionalidade (Figura 2d).

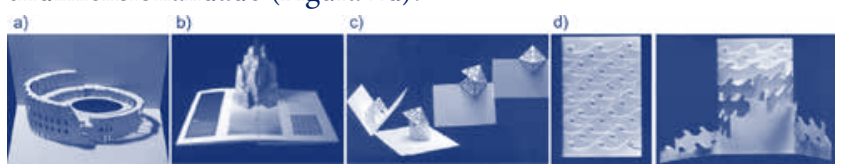

Figura 2: a): origami 90 (Biankini, 2009); b): origami 180 (Esher, 2011); c): origami $360^{\circ}$ (Ueno, 2003); d): origami 0 (Ueno, 2003).

Dentre as quatro modalidades de origami arquitetônico, esta pesquisa foca no estudo de $90^{\circ}$, que pode ser aplicada na representação e compreensão de obras arquitetônicas já construídas, bem como na elaboração volumétrica de croquis e esboços das primeiras fases projetuais.

\section{Metodologia de estudo}

Esta pesquisa se motivou a elaborar uma metodologia de criação de origamis arquitetônicos, por meio de modelos práticos de diferentes obras de arquitetura. Todo esse estudo visa apresentar uma nova alternativa de elaboração de maquetes e representaçôes tridimensionais, importantes para estudos volumétricos e espaciais.

O processo da pesquisa que envolve este tema teve início com um estudo bastante prático com montagem e recorte de modelos já prontos, estudando a forma de representação da obra em questão e também da sua planificaçáo. Parte da bibliografia utilizada na pesquisa foi encontrada em livros contendo modelos da técnica já prontos e outros com a devida planificação da obra para recorte e montagem. Boa parte dos modelos encontrados foi confeccionada pelo professor Masahiro Chatani (1999) e também de outros artistas da arquitetura do papel como Ingrid Siliakus (2009), Maria Victoria Garrido Bianchini (2009) e Joyce Aysta (2009).

O passo seguinte consistiu na leitura de artigos referentes à técnica e também do estudo mais aprofundado da planificação dos modelos. Foi nessa etapa que a lógica do origami montado ficou mais clara, pois a planificação já existente foi refeita em software $\mathrm{CAD}$ (AutoCAD), tendo o cuidado de verificar as dimensóes entre as linhas de dobra e o volume analisado. Refazendo a planificaçâo de alguns modelos, pôde ser verificado que algumas decisóes de planejamento somente puderam ser percebidas após a materialização dos modelos, que nestes casos utilizou a tecnologia do corte a laser.

Concluída a etapa de estudo da técnica por meio de modelos prontos, iniciou-se o processo de criaçáo de novos modelos a partir de imagens. As fotos escolhidas deveriam conter informaçóes 
como profundidade e ângulo de visão escolhido para o origami arquitetônico. A partir disso, foi possível criar modelos utilizando a proporção e os elementos característicos de cada obra como partido para elaboração dos mesmos.

Durante a criação dos próprios modelos, notou-se que as obras escolhidas possuíam singularidades arquitetônicas que deveriam ser ressaltadas, utilizando então, as estratégias de representação. Para cada nova forma estudada foram sendo observados diferentes métodos de representação. Com isso, pôde-se perceber que não existe apenas uma maneira de representar uma obra arquitetônica, pois existem inúmeras possibilidades de criação, seja a partir de ângulos diferentes de visualização ou mesmo nos detalhes escolhidos para serem enfatizados.

Criando diferentes tipos de origamis arquitetônicos a partir de imagens, chegou-se a uma metodologia, resultado das experiências anotadas em cada modelo. A elaboração dos modelos deixou claro que o processo criativo envolvia não somente a observação das imagens e planificação, mas também os croquis e testes físicos manuais. Somente após todo esse processo, que o origami arquitetônico estaria pronto para finalizaçáo, sendo então planificado nos sistemas CAD para posterior materialização, com corte laser.

\section{Materiais e métodos}

A técnica do origami arquitetônico surge como uma nova possibilidade de representaçáo tridimensional. Semelhante ao de uma maquete física, esse tipo de modelo passa por uma simplificação visando expressar as características essenciais de uma determinada obra arquitetônica. Essa simplificação também é observada nos materiais utilizados, que se resume a apenas um: o papel. Por esse motivo, para que se tenha uma representação estável e uniforme, orienta-se o uso de papéis com gramatura superior a $130 \mathrm{~g} / \mathrm{m}^{2}$, de livre escolha quanto ao tamanho, formato e textura, dependendo do resultado que se deseja obter.

O corte a laser desempenha um papel bastante importante na elaboração dos modelos, proporcionando uma interaçáo rápida entre a informação digital e sua materialização. Quanto à utilização da máquina, foram testados diferentes tipos e gramaturas de papéis, além dos ajustes das relativas potências e velocidades de corte ou vincos no papel, resultando num modelo preciso e com um ótimo acabamento.

\section{Definição da técnica}

$\mathrm{O}$ origami arquitetônico com $90^{\circ}$ de possui a singularidade de estar fixo no papel e consiste num volume único gerado apenas pelos cortes e dobras. Entretanto, deve-se respeitar os padróes de dobradura para satisfazer a condição de fechamento do modelo $\left(\right.$ de $90^{\circ}$ para $\left.0^{\circ}\right)$.

Essas regras são baseadas na geometria descritiva que, no origami arquitetônico, é utilizada uma dobra principal para montar o modelo, definida aqui como "linha zero". Todas as representaçôes desta técnica são feitas a partir de polígonos planos, sendo a planificação do mesmo a chave para aplicaçáo das condiçóes de fechamento. Além da linha zero, existem outros dois tipos de dobradura: a dobra vale e a montanha. Os cortes servem para destacar as faces do papel e gerá-las sempre a partir da linha zero criada.

Esses padróes de dobradura e os cortes no papel geram uma estrutura que faz a transição do $2 \mathrm{D}$ para o $3 \mathrm{D}$, pois a figura formada ressalta a ideia de tridimensionalidade, porém suas faces são planificadas. Isso ocorre porque os pedaços de papel cortados e dobrados para criar os volumes deixam espaços vazios, sem o fechamento lateral. Dessa maneira, o modelo criado não gera um objeto totalmente tridimensional e nem bidimensional, resultando num intermédio dessas duas formas, o 2.5D.

\section{Definição de termos}

Confeccionar e elaborar modelos de origami arquitetônico é um exercício constante de observação e testes e as diferenças observadas na sua planificação resultam em diferentes efeitos a serem explorados. Com isso, é necessário diferenciar as diversas terminologias e notar como cada uma delas se associa na estrutura final do origami.

Linha zero: Essa linha monta o modelo e é a responsável por determinar as relaçóes de volumetria. Todas as dimensóes têm por base essa linha, que pode ser localizada em diferentes posiçóes da folha, náo necessariamente no meio da mesma, variando pelo tipo de objeto que será representado (Figura 3a). Plano horizontal e vertical: a folha de papel dobrada forma $90^{\circ}$ gerando dois planos: um vertical e outro horizontal, base de apoio do modelo (Figura 3b). Dobra vale e dobra montanha: na planificação, a dobra vale e montanha também correspondem às linhas que estáo associadas à linha zero (origem). A distância entre uma dobra vale ou montanha irá determinar a altura do volume. Esses dois tipos de dobras existem um em funçáo do outro e juntos compóem a estrutura (Figura 3a). Face volumétrica e face de sustentaçáo: para criar diferentes formas, as faces devem representar uma determinada figura. As faces volumétricas expressam uma fachada ou elemento arquitetônico em si. Já as faces de sustentação servem para montar o modelo. Sempre que a face volumétrica for paralela ao plano vertical, por exemplo, a face de sustentaçáo será paralela ao plano horizontal (Figura 3c). Cortes verticais e horizontais: sáo os cortes no papel que delimitam as faces volumétricas e de sustentação, estando associadas com os limites das dobras vale e montanha. Quando a linha zero é projetada na horizontal o efeito de tridimensionalidade é obtido com cortes na vertical, e quando projetada na vertical os cortes são feitos na horizontal. Essa relação entre a linha zero e os cortes fazem com que as faces se destaquem do plano horizontal ou vertical, dependendo da estrutura do modelo (Figura 3c). Detalhes construtivos: a ferramenta utilizada para representar os detalhes construtivos são os cortes no papel e a remoção desses pedaços da figura, portanto, esse efeito é criado a partir dos vazios numa face que seria totalmente plana. A combinação das dobras, cortes e destaque dos detalhes construtivos permitem o reconhecimento de uma obra retratando os seus aspectos mais relevantes. Relaçóes geométricas: as condiçôes de existência dos origamis arquitetônicos são embasadas na geometria descritiva. Desse modo, as relaçóes geométricas podem ser analisadas através da planificação do modelo (Figura 3d). Os volumes criados sempre teráo como linha base a linha zero e as dimensóes e afastamentos dessa linha resultam nos deslocamentos dos volumes. 


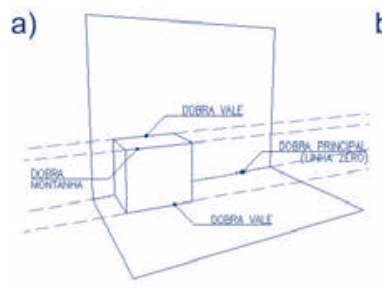

b)

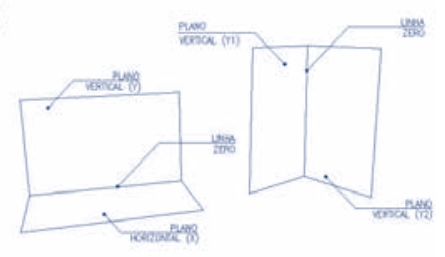

c)

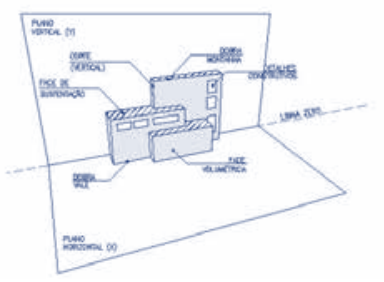

d)

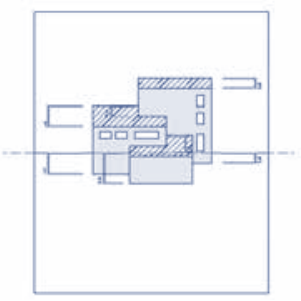

Figura $3:$ a): diferenciação entre dobra vale, montanha e linha zero; b): diferenciação entre plano horizontal, vertical e linha zero; c): diferenciação entre face volumétrica, de sustentação e detalhes construtivos; d): relaçôes geométricas na planificação. Elaborado pelos autores.

\section{Metodologia de confecção de modelos}

Após estudo da técnica e testes de diversos modelos, chegou-se a uma metodologia que contém todo o processo de elaboração de um origami arquitetônico, desde a escolha das imagens da obra até a produção final do modelo.

Para ilustrar a concepção passo a passo de um origami arquitetônico, a obra escolhida foi a Catedral Metropolitana de Florianópolis. Ao iniciar um origami arquitetônico é necessário ter definido qual ângulo da obra se quer representar; no caso deste exemplo optou-se pela fachada frontal da mesma. Para compreender a volumetria da obra, o ideal é que haja pelo menos duas imagens de referência, para que os aspectos de profundidade e proporção possam ser percebidos nas imagens (Figura 4a).

Após a análise da volumetria da obra por meio das imagens, inicia-se a planificaçáo do modelo no software AutoCAD 2D. Para isso é necessário que a imagem base (por onde serão traçadas as linhas) tenha menos distorçóes de perspectivas possíveis. Inserida a imagem, os limites (eixos) verticais e horizontais da obra que se pretendem demarcar são definidos, para que possa ser traçado o limite de cada volume já identificado (Figura 4b). Recomenda-se que para facilitar o reconhecimento das linhas auxiliares criadas, cada volume seja feito de uma vez.

Conforme citado anteriormente, recomenda-se utilizar uma imagem sem muita distorção pela perspectiva, porém nem sempre isso é possível, por isso, é necessária a comparação entre duas imagens de ângulos diferentes, no mínimo. Comparando as duas imagens, são observadas as proporçóes entre as partes da obra e, com isso, ela poderá ser representada com maior realismo, semelhante ao desenho de uma fachada que utiliza as dimensóes em verdadeira grandeza. Na figura 4c se observa uma delimitação mais clara de cada volume e a observância das proporçóes.

Demarcados os volumes, a próxima etapa de representação é a identificação dos detalhes construtivos que se quer representar e que são mais relevantes para a identificação da obra (Figura 4d). Representados todos os detalhes construtivos, orienta-se a utilizar uma cor de linha ou hachura para cada volume e grupo, a fim de diferenciar um dos outros nas próximas etapas.

Concluída a etapa de representação dos detalhes construtivos, o modelo está pronto para tornar-se um origami arquitetônico. Esse processo inicia-se com a definição da linha zero e a partir dela serão definidas as distâncias entre as dobras vale e a linha zero (Figura 4e). Recomenda-se que cada volume seja deslocado de uma vez, para facilitar o reconhecimento das distâncias que serão aplicadas (Figura 4f). Nesta etapa a imagem de fundo pode ser retirada, utilizando apenas as linhas criadas como referencial para concepção do origami arquitetônico.

Realizados os deslocamentos em relação à linha zero, serão demarcadas as distâncias entre a dobra vale e a linha zero também no plano vertical, após a face volumétrica, delimitando e criando, então, a face de sustentação (Figuras $4 \mathrm{~g}$ e $4 \mathrm{~h}$ ). Como podem ser observadas nas imagens anteriores, as mesmas caracterizam-se por apresentar volumes simples, porém, quando mais de um volume possuir a mesma face de sustentação, as distâncias serão subdivididas, conforme ilustrado na figura $4 \mathrm{i}$.

Finalizada a etapa de definição das faces de sustentação, serão demarcadas as dobras vale e montanha, já previamente identificadas para execução das faces volumétricas e de sustentação (Figura 4j). Como pode ser observado nas figuras, o origami arquitetônico representa somente o "corpo" da Catedral. Caso se deseje representar outros elementos, esse novo volume pode ser acrescentado do restante do modelo, como no exemplo da escadaria, que foi anexada aos outros volumes já montados respeitando a geometria descritiva (Figura 4k).
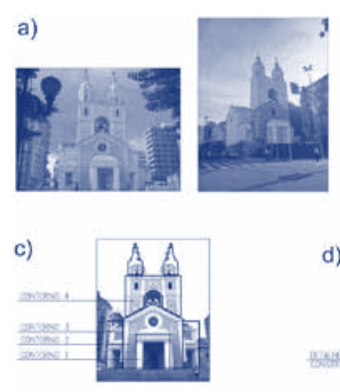

f)

f)

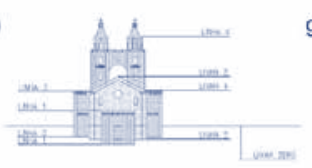

i)

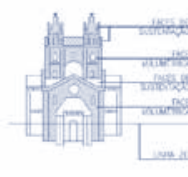

d)

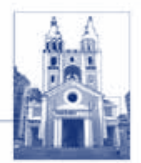

g)

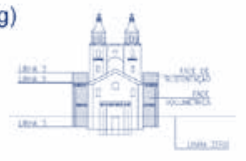

j)

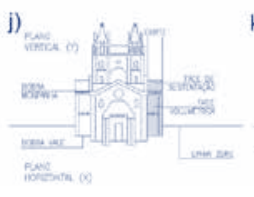

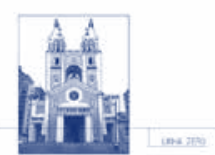

h)

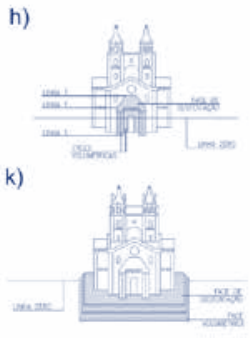

)
Figura 4 a): identificação dos volumes da Catedral; b): delimitação dos eixos verticais, horizontais e contorno do volume; c): demarcaçáo dos volumes; d): representaçã́o dos detalhes construtivos; e): demarcação da linha zero; f): deslocamento dos volumes em relação à linha zero; g) e h): delimitação e criação das faces de sustentação; i): subdivisão de distâncias, conforme sobreposição de 
volumes; j): demarcação da dobra vale, montanha e demais terminologias; $\mathrm{k}$ ): volume da escadaria adicionado. Elaborado pelos autores.

Realizadas todas essas etapas, o modelo origami arquitetônico está pronto para corte e montagem. A figura 5 a mostra a representação da Catedral Metropolitana de Florianópolis em foto e em origami arquitetônico executado nesta pesquisa.

Definido o método de execução para elaboração dos origamis arquitetônicos, esse passo a passo serve como um guia. Adquirido maior familiaridade com a técnica e o seu processo de execução, é possível representar os mais diversos exemplos de obras arquitetônicas (Figuras 5b e 5c).

No decorrer do desenvolvimento de novos modelos percebeu-se que certas obras possuem particularidades que a técnica original, utilizando apenas uma folha de papel, não consegue representar tấo fielmente, possuindo certas limitaçóes.

Dessa forma, tentou-se representar algumas obras com mais de uma folha de papel, funcionando como camadas para representação dos volumes. A figura $5 \mathrm{~d}$ apresenta uma edificação na técnica com uma e duas folhas de papel. Já a figura 5e representa outra edificação na técnica com duas folhas de papel. Em ambas, a obra representada possui um maior grau de complexidade e a utilização de duas folhas proporciona um maior detalhamento e realismo com a obra arquitetônica original.

Foram realizados testes com três folhas de papel também, aumentando o grau de complexidade do origami arquitetônico, em que é necessário unir cada camada (folha de papel) e estabelecer as relaçóes geométricas para cada uma delas separadamente. $\mathrm{O}$ interessante dessa nova concepçáo é que as folhas unidas ampliam a noção de perspectiva do modelo (Figura 5f).

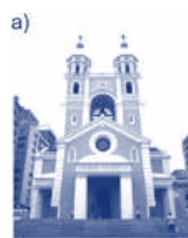

c)

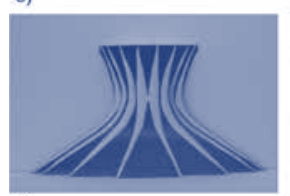

e)
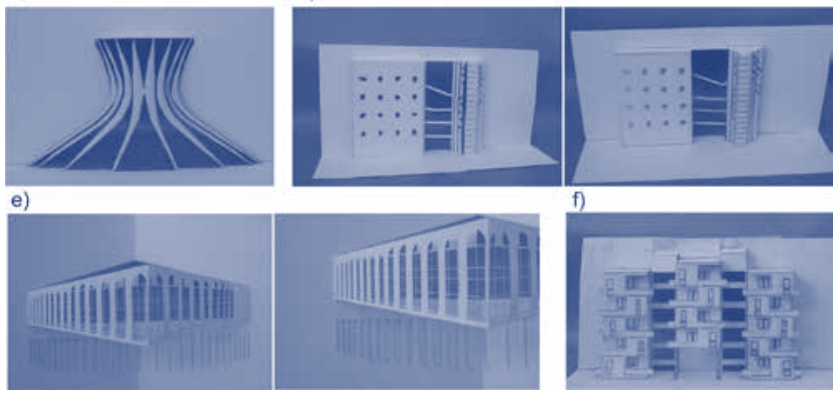

Figura 5: a): Catedral Metropolitana de Florianópolis e seu origami arquitetônico; b): representação de curvas de nível pela técnica; c): origami arquitetônico da Catedral de Brasília; d): origami arquitetônico do SESC Pompéia em folha única e dupla; e): origami arquitetônico do Itamaraty; f): origami arquitetônico de um trabalho acadêmico feito a partir de um croqui . Elaborado pelos autores.

\section{Conclusão}

A partir desses estudos e avaliados os processos e resultados, esta pesquisa presencia, intrinsecamente nesta metodologia, um resultado além de um produto (origami) de papel. Percebe-se no processo de concepção do origami arquitetônico uma compreensão do objeto estudado que não envolve essencialmente apenas informaçôes físicas, tais como suas dimensóes e proporçóes. Este traz um entendimento prático da espacialidade e volumetria, semelhante ao da confecção de maquetes físicas, onde os estudos dessas relaçôes se tornam mais próximos e evidentes. Assim, proporciona-se um raciocínio de criação para projetos próprios onde a espacialidade, criada por planos e volumes, forma-se com clareza na mente do projetista.

No decorrer da pesquisa observou-se que a metodologia pode ser aplicada não somente com base em imagens fotográficas de arquiteturas existentes, mas também a partir de croquis, desenhos e sketches na fase de desenvolvimento de um projeto, em que o modelo seria uma ferramenta projetual para análise e estudos dos volumes criados.

\section{Agradecimento}

Agradecimentos à UFSC e ao grupo PET/Arq UFSC pelo apoio nas atividades de pesquisa, ensino e extensão e ao Laboratório PRONTO3D (www.redepronto3d.com) pela disponibilização da cortadora a laser para o desenvolvimento da pesquisa.

\section{Referências}

Bianchini, María Victoria Garrido; Siliakus, Ingrid; Aysta, Joyce. The Paper Architect: Fold-it-yourself buildings and structures. United States: Potter Craft, 2009.

Carroll, Lewis; Sabuda, Robert. Alice's adventures in wonderland - pop up. Simon \& Schuster, 2010.

Chatani, Masahiro; Kihara, Takaaki. Origamic Architecture: Worldfamous Buildings. Tokyo, Japan: Shokokusha, 1999.

Escher, M. C. Pop-ups M. C. Escher. Los Angeles, Califórnia, EUA, 2011

Hermmerling, Marco. Informed Material. XV Congresso Sigradi 2011.

Jackson, Paul. The Pop-Up Book: Step-by-Step Instructions for creating over 100 Original Paper Projects. New York: Owl Books, 1993.

Jackson, Paul. Cut and fold techniques for Pop-Up designs. London: Laurence King, 2014.

Jackson, Paul. Folding techniques for designers: From sheet to form. London: Laurence King, 2011.

Mitani, Jun; Susuki, Hiromasa. Computer aided design for Origamic Architecture models with polygonal representation. Tokyo, Japan: J. Ipsj, 2003.

Papiromano. Papiroflexia para todos. Disponível em: <http:// papiromania.blogspot.com.br>. Acesso em: 10 abr. 2014.

Ueno, Thaís R. Do origami tradicional ao origami arquitetônico: uma trajetória histórica e técnica do artesanato oriental em papel e suas aplicações no design contemporâneo. Bauru, Brasil, 2003. 